\title{
Drug Designing An Ayurvedic Perspective
}

\author{
Abhilash Mullasseril \\ (Mullasseril, Veliyanad Post., Ernakulam Dist., Kerala-682 313, India)
}

\begin{abstract}
The Computer Assisted Drug Designing and Discovery is an emerging area of Scientific research with great importance. The knowledge abstraction for achieving the goals of this research is not only limited to modern computational chemistry or pharmacy. The computational scientists are ready to widen their knowledge based on all branches of medicines and we can also find relevant and significant information from alternative medicines like ayurveda. This paper aims to correlate the modern drug discovery concept to the traditional Indian system of medicine known as Ayurveda. The computer assisted drug designing is the modern concept in which the concept of Artificial Intelligence is widely applied throughout the processes. The research for improvising methodologies adopted many terminologies from the different branches of knowledge and made the field more interdisciplinary in nature. The philosophical bases of the Ayurvedic concept of Aushadha and Tridosha theory of diagnosis are also found relevant in the field of modern drug discovery and development and are able to give new insights to the scientists and medicinal chemists.
\end{abstract}

Keywords - Drug, Drug discovery and Development, Lipinski rules, Aushadha, Pathya, Medicinal Chemistry, Ayurveda, Alternative medicines.

\section{INTRODUCTION}

The field of research in medicinal chemistry became multidimensional and is in a boom of swift development by the introduction of computers. The speed of computers and problem solving skill of Artificial Intelligence contributed much in the field of both academic and industrial research. The medicinal scientist attempts to design and synthesize novel drugs which need more interdisciplinary skills with enthusiasm to acquire interdisciplinary knowledge [1]. The speed of Artificial Intelligence over the Natural Intelligence made the field more machine dependent than human power dependent. The human power reduced to a considerable extent but the need of interdisciplinary skilled persons became very urgent in this field of research. The machine can perform the program as per the instructions of the programming scientist and the success of it varies with the interdisciplinary skills of the programmer. The terms used in computational designing must be defined precisely and accurately to make a successful programme. The natural intelligence must be used in a constructive way without any presumption alone can define the glossary. This paper aims to compare the term drug using in the literature of modern medicine with the Aushadha concept of Ayurveda the traditional system of medicine in a scientific way.

\section{MATERIALS AND METHOD}

These studies try to correlate the modern drug designing concept with the Ayurvedic concept of Aushadha on their philosophical bases. The area being interdisciplinary the method was purely knowledge based without having any presumptions or considerations. The scientific and philosophical observations and inferences are given equal importance. Then only the real enrichment of knowledge for application can result. Traditional and modern sentence analysis methods were used to acquire the correct knowledge without any presumption. The modified method of sentence analysis developed by the Indian scientists of IIIT was used to reach the aptness of the meaning [2].

\section{MODERN DEFINITION OF DRUG}

The problem to define the word Drug accurately and precisely is still under the controversy and a challenging one in front of medicinal scientists and pharmacists. The introduction of computers to the field of drug discovery and research need more accurate and precise definitions to the fundamental terms used for programming. The term Drug is found defined in many ways in many available literatures of medicinal chemistry. One definition is that a pharmaceutical agent that has a desired biological effect on the living system. This definition is not complete as there exists a probability that a pharmaceutical agent can act with biological system both constructively in a good manner and adversely in a bad manner giving the possibility for both the Good and Bad Drugs and which itself is quite confusing [3]. Even the good drugs are also found distinctly dangerous in some cases. For example Morphine an excellent analgesic, Barbiturates used for general 
anaesthesia are good drugs but with serious side effects and bad drugs like Heroine which is still being used in limited doses under strict control in critical stages of cancer to overcome the depression with a euphoric effect. Currently prescribing Pt metal containing medicine Cisplatin is also not found safe because of serious side effects and the emergence of metal resistant tumour cells- one of the most challenging problems for oncology researchers. Some newly invented drugs showed side effects including fatal deaths at the post marketing phase and has to be given attention. The well-known and popular antibiotic penicillin and its derivatives are also not free from the side effects [4]. Thus the definition becomes irrelevant at many times. This lead to a new modified definition for the concept called drug as chemicals that interact with a biological system to produce a biological response. Still the confusing problem gives headache to the drug designing and discovery people who concentrate more on the computational solutions that need apt defining and controlling rules. The modified modern definition of drug is that chemicals that prevent disease or assist in restoring health to diseased individuals. This definition is also lacking in certain aspects like health tonics which cannot be included as they are prescribed for the healthy individuals. This definition is one of the most comparable one with the ancient Ayurvedic definition, but the concept also including the heath tonics $[5,6]$.

\section{III.1. MODERN SOLUTION- LIPINSKI RULES}

The modern definition of drug is also not enough for a programmer to define the object called drug. This problem was solved to a considerable extent by Lipinski and coworkers by taking steps courageously on formulating the limiting rules by analyzing more than 2500 drugs avoiding any kind of presumptions. He formulated the famous Lipinski rules of five or simply the rules of five and is the present fundamentals of the drug discovery. He considered the molecular weight, number of hydrogen bonding groups and the hydrophobic character of the drug while formulating his limiting rules [7]. This rule was essential for the modeling scientists to limit the search to find the drug candidates. After analyzing many of the presently prescribing drugs they formulated four criteria about the chemicals that have to be termed as Drug.

1. The substance should have a molecular weight of $500(5 \times 100=500)$ or less.

2. It should have fewer than Five $(5 \mathrm{X} 1=5) \mathrm{H}$-bond donating functions.

3. It should have fewer than Ten $(5 \times 2=10) \mathrm{H}$-bond accepting functions.

4. The substance should have a calculated $\log \mathrm{P}$ between approximately -1 to 5 .

In short the substance should have a comparatively low molecular weight, be relatively non-polar and partition between an aqueous and a particular lipid phase in favour of the lipid phase but at the same time possess perceptible solubility. Eventhough many oral drugs obey these rules considerably but are not completely the perfect ones at many practical levels and still need modification. The importance of the number five and its multiples observed during the studies was not supported by any of the theoretical concepts of the modern science. The fourth rule is relating the chemical with the biological parameter termed log $\mathrm{P}$, the partition coefficient between water octanol systems a mimic of Blood Brain Barrier (BBB). However, it is not completely the perfect one at many practical levels and still need modification. The most renowned antibiotic penicillin itself and its degradation products, such as penicilloic acid and also monopenicilloyl amides, may elicit immediate reactions in patients allergic to penicillin even though it obeys the rules of five. The penicillin and its degradation products are immunochemically monovalent, since they are similar in size or smaller than a single antigenic determinant. Nevertheless they cannot safely be classified as true monovalent elicitors of anaphylactic type reactions since they possess, via their thiazolidines, the potential to react chemically with suitable peptides and proteins, thereby forming oligohaptenic conjugates. Thus the side effects of the drugs that obey the Lipinski rules cannot be determined accurately and precisely without performing the classical clinical methodologies. There are newly introduced modern in-silico methodologies which may help to limit the QSAR studies to a considerable extent when used intelligently to support with acceptable results. There are molecules that do not obey the rules but are found to be better drugs with good approval. For example many of the traditionally used macro molecules, statins, metal containing drugs etc. are found not suitable according to this definition and are found exemptions to the rules of five. The polymorphism exhibited among the drugs and the effect of the same on biological responses was not the subject matter while formulating the limiting rules. Thus the rules of five also have to be revised accordingly. Further research is going on the same which can even extract more traditional knowledge from the alternative systems of medicines to make the rules a perfect.

\section{III.2. Alternative systems of medicine}

Alternative medicines used in the traditional system are comparable with the modern medicines with lesser side effects. The importance of philosophies used in alternative systems like Ayurveda and Homeopathy for defining a drug is also worthwhile in comparing. According to Homeopathy the substance that causes undesired effect at large quantities or macro levels can act as the medicine at infinite dilutions or micro levels for that undesired effect. This concept of Homeopathy is one of the bases of the modern nano pharmaceutics and 
venom research. But it is observed that the philosophy of Homeopathy fails to give an acceptable reason for the observed difference in the biological responses at macro and micro levels. Now very recently the concept of nanotechnology and nanomedicines got a boom in the field of modern research and which can explain the difference in micro and macro level behaviour of same compound at least in a periphery level. This might have been due to the possible polarity reversal of the drug at the micro level (Umpolung) and which interacts with the body to form apt modification to the antibodies by forming antibody drug conjugates to neutralize the recognized antigens. This might have been aroused due to the basic difference in the philosophies of modern and traditional systems of medicine. The alternative system Ayurveda believes that the diseases are not from the environment but as a result of state of mind. Modern psychology also supports the fact that symptoms of almost any disease can be induced in hypnotic subjects by suggestion. This indicates that the cause of the disease is developed or induced by artificially or naturally in one's own mind. The healing of the disease can also take place mentally and it is interesting to consider the philosophical background of traditional systems of medicine. The Ayurveda philosophy points that the treatment is to be given to the patient and not to the symptoms of disease. Ayurveda focuses more on the root cause of the disease and tries to eliminate the same from the body by applying the Tridosha theory of diagnosis and which is found relevant even in modern times [8].

\section{III.3. The aushadha concept of ayurveda}

In the traditional Indian Systems of Medicine comprising of Ayurveda, Unani and Siddha, drugs of plant (90\%), animal and mineral origin (10\%), are used in their natural or so called "Crude" forms singly or in their mixture or in combination, to make a compound preparation of formulation. The term Aushadha is commonly translated and used instead of the word Drug in common parlance. The word Aushadha has many other dimensions that have to be considered while translating the Sanskrit word. The word Aushadha means the active ingredient obtained or prepared from Oshadhi, the herb or medicinal plant or simply medicament or medicine in general. Aushadha also includes the minerals in a wider sense. The Sanskrit word Aushadha thus includes not only simply drugs or medicament of herbal origin but also minerals or metal containing drugs. One of the basic texts or samhitas namely Charakasamhita defined Aushadha in a more scientific manner. The Aushadha is something (object) with pathya (certain rules), that is to cure completely the treated disease. The aim is to re-establish the prakrti the original status of the body with all cured nature. Here arises a question to the author that the definition excludes the drugs or tonics that are used by healthy persons. For a healthy person bheshaja (medicine) is indicated to improve vital energy and for the suffering patient it is to cure the disease. There are many Rasayanas (promotive measures) for the healthy person to increase the life, power of memory, quality of intellect by providing youthful nature to the body. The Vajikarana (aphrodisiacs) is also for healthy person to make suitable offspring. The concept of health tonics are covered under the definition which was excluded by modern definition. For a healthy person both Rasayana and Vajikarana are the two types of Aushadha to be used to increase vital energy. Thus the definition of Aushadha given in the ancient text is found more accurate as it covers not only the chemicals that can act as drugs for a patient but also the health tonics for a healthy person to maintain his health.

\section{III.4. The Patent Concept Used In Protecting The Medicine}

Abridgers of the scientific knowledge of Ayurveda usually compressed the scientific ideas to fewer words to convey all the meaning in a nutshell and to memorize easily. They beautifully expressed the idea without loosing its originality in the scientific language Sanskrit. But it created a major problem when we try to interpret the old sciences and their philosophical ideas today in this modern era. The problem is that they developed in traditional societies, before the use of printing and the manner of teaching was authoritarian. The same Sanskrit word may be used in the text in different formulations for mentioning different drugs or plants. A real traditional practitioner or physician or disciple alone can understand the apt meaning of the word used in the texts. This was to protect the formulation in a traditional way which is comparable to the modern patent protections. The original formulation was only known to the traditionally trained practitioners and his students or followers. They used many new words and even assigned new meanings to the terms different from the usage in common parlance for limiting the usage. But this created a problem that later students of Ayurveda cannot able to interpret the apt meaning as this tradition was lost due to many internal and external reasons in India. The various dictionaries (Nighantus) made many terms merely synonyms by avoiding their minute differences for easy usage. Eventhough they simplified the terms this method made the later students to misunderstand the terms used in classical texts. The origin of this scientific method of using words is found comparable to the works of Lipinski in which he formulated the rules to define the concept drug in the modern times. The Lipinski rules as such cannot be used to define the Ayurvedic drug but it is interesting to correlate the results presented in the ancient texts while formulating the definition.

\section{RESULTS AND DISCUSSION}

The correlation of both the philosophies of modern and alternative medicines was achieved by giving equal importance to both schools of medicines for knowledge enhancement. The correlation obtained for the Drug concepts of modern sciences and Aushadha concept of Ayurveda is found relevant. 


\section{IV.1. Correlation Of Lipinski Rules Of Five And Aushadha Concept}

The sentence analysis of the definition of the word Aushadha is done in the traditional way of interpretation by selecting the apt meaning from different possible meanings of the used words and the definition obtained is translated. For this the Indian method for interpreting the meaning using a Paninian perspective is used. As a result of sentence analysis the definition of Aushadha is achieved and is as follows. The Aushadha is the material (object) that cures the treated disease when observed with Pathya (rules of medication) that aims at the reestablishment of the healthy nature and the mental status (Prakrti) of the patient with a complete cure from the diseases or ailment. The term pathya has many dimensions of meaning that from likeness to medication rules through the adjustment to the treatment prescribed. The term pathya is translated even as the drug itself by many commentators but which I personally feel without any presumption that is better to consider as rules of medication as evident from sentence analysis. Here it is worthwhile to compare the rules of five for defining the drug with the term pathya. A chemical that obeys the rules of five can be termed as eligible drug candidate or leads and similarly the rules of medications followed in alternative systems of medicines were the actual controlling rules to make the drugs more pontent. On analyzing these we can observe further that the concept or logic behind the Lipinski rules was successfully practiced by the followers of alternative system of medicine without knowing the importance. The importance of hydrophobic and hydrophilic nature of the chemicals was very well known to the ancient formulators while preparing the drugs as evident from the different combinations or Yogas for preparing the medicines according to classical texts. The bases for preparing the drugs were selected as water, oil and ghee. Both oil and ghee are more hydrophobic and can dissolve the hydrophobic chemicals present in the drugs in to the bulk (Ghrita and Taila). The drugs prepared in the watery bases (Kahsaya/Kwath) contain more hydrophilic substances. They effectively use intelligent combinations of these drugs while treating a patient after understanding his prakrti. The special preparations like Asava and Arishta rich in natural alcoholic content can act as a supportive for easy interchange of active ingredients between the watery and oily layers for attaining the desired therapeutic effect in the body. Some medicinal formulation uses both water and ghee while being administered for better result. For example the Indukantam ghritam is recommended for administration with Indukantam kashayam by traditional practitioner (differences in opinion may be there). The crude plant drugs used for making these are almost the same for watery bases and for oily bases as evident from texts. In the same way Vidaryadi kashayam and Vidaryadi ghritam together are prescribed for ailments to get good results. In the same way oils were administered with kashayas. These prescriptions have shown good therapeutic results with the best patient satisfaction. Here knowingly or unknowingly we were utilizing the hydrophilic and hydrophobic nature of the pancamahabhutas to balance the tridosha of the body to reestablish the the healthy nature (prakrti) of the patient. I agree that the limiting rule of molecular weight was not considered as an essential rule in the practice of alternative medicines. There were many exemptions to this rule as stated earlier and many modified the limiting values recently according to their observations. They suggested a limiting value of 900 to the molecular weight which is further a multiple of three which has importance in Ayurveda theories. The fourth rule that correlates $\log \mathrm{P}$ a biological parameter with the structure of the lead understudy has much importance and is comparable with the Tridosha theory of diagnosis at a very periphery level. Adopting the bases of the Tridosha theory in a scientific manner may help to improvise the fourth rule or the biological parameter rule. A suitable lead can be termed as a drug only when it achieves the goal or aim to re-establish the healthy nature (Prakrti) of the patient after treatment. The same drug successful to one may or may not be the right one for another patient. This can be successfully explained or managed by the tridosha theory of Ayurveda diagnosis. The modern definition of drug as chemicals that prevent disease or assist in restoring health to diseased individuals is one of the most comparable one with the ancient Ayurvedic definition.

\section{CONCLUSION}

The philosophical bases of Alternate medicine when scientifically studied can be usefully adopted for improvising the modern scientific methodologies. By comparing the definition or rules of the modern modelling along with the traditional definitions through the Tridosha theory of diagnosis the drug discovery team can succeed more towards the goal with more effective drugs. The real importance of the number five in the rules of five is still has to be answered theoretically but can found a plausible basis in the ancient Indian concept used in Ayurveda called pancikarana a traditional system of matter analysis. The importance of the philosophical bases of other odd numbers like one, three, five and seven and even numbers like two, six and eight among many others in Ayurveda one of the main branches of alternative medicines could be found much relevant whenever we require supporting the observed values of numbers. The knowledge from any sources irrespective of their origin has to be utilized wisely without any prejudice with an open-minded manner. Based on the knowledge gained from ancient methods and from modern education developed a new concept called Distribution of Active Electrons for the designing of both molecules and synthetic routes was developed and successfully applied to both computer 
assisted drug designing and laboratory synthesis of the designed drugs. Further researches are going on the application of the developed concept to more and more drug like molecules.

\section{REFERENCES}

[1] Mitscher, A. Lester, Drug Design and Discovery: an overview in Textbook of Drug Design and Discovery (Taylor \& Francis, London and New York, 2004).

[2] V.Chaitanya, R.Sangal, Natural Language Processing A Paninian Perspective, (New Delhi:PHI, 1999).

[3] G.L. Patrick, An Introduction to Medicinal Chemistry (Oxford:Oxford University Press, 2009).

[4] R.Guenin, C.H.Schneider, Penicillin derivatives are true monovalent elicitors of anaphylactic reactions. Immunology. 52, 1984, 189-96.

[5] IUPAC web site http://www.iupac.org H Van de Waterbeemed (1997) Glossary of terms used in computational drug design. Pure \& Appl. Chem. 69(5), 1137-1152.

[6] Carakasamhita : Read vedic literature in Sankrit Maharshi University

[7] C.A.Lipinski, F.Lombardo, B.W.Dominy and P.J.Freeney, Experimental and computational approaches to estimate solubility and permeability in drug discovery and development settings. Adv. Drug. Deliv. Rev., 23, 1997, 3-25.

[8] Rama Vaidya Observational therapeutics: Scope, challenges, and organization. Journal of Ayurveda \& Integrative Medicine, 2(4), 2011. 